\title{
PENGEMBANGAN KAWASAN EKOWISATA DI KECAMATAN MEMPURA KABUPATEN SIAK
}

\author{
Wasiah Sufi, Nurpeni, Fara Merian Sari \\ Fakultas Ilmu Administrasi Universitas Lancang Kuning \\ Email :wasiahsufi@unilak.ac.id
}

\begin{abstract}
Siak Regency is one of the areas in Riau that has the potential to develop tourism in the region, precisely in Kecamatan Mempura include: natural potential, historical potential, socio-cultural potential, and the potential of agriculture and condensation. They are: Tangsi Belanda, Tomb of Sultan Buang Asmara, Kotler House and Office, Datuk Pesisir House, Dome of the Dome, Wedana Office at Lower Hilir. The tourism sector requires a good development of tourism. The potentials that are owned can be developed and get maximum results. From the explanation the authors use descriptive research type using qualitative research methods with the focus of research 1.Policy Ecotourism development in Siak District 2. obstacles in ecotourism development in Kecamatan Mempura Siak regency. The research results explained that the development of ecotourism area in Districk Mempura is still not yet Maximum because there are still many obstacles faced by local government Mempura.
\end{abstract}

Keywords: Policy, Development, Ecotourism.

\section{Abstrak}

Kabupaten Siak merupakan salah satu daerah di Riau yang berpotensi untuk mengembangkan pariwisata di daerahnya, tepatnya di Kecamatan Mempura diantaranya meliputi: potensi Alam, Potensi sejarah, potensi sosial budaya, dan potensi pertanian dan perkembunan. Yaitu: Tangsi Belanda, Makam Sultan Buang Asmara, Rumah dan Kantor Kotler, Rumah Datuk Pesisir, Makam Kubah, Kantor Wedana di Benteng Hilir. Sektor pariwisata memerlukan suatu pengembangan kepariwisataan yang baik.agar potensi yang di miliki bisa dikembangkan dan mendapatkan hasil yang maksimal. Dari penjelasan tersebut penulis menggunakan jenis penelitian deskriptif dengan menggunakan metode penelitian kualitatif dengan fokus penelitian 1.Kebijakan Pengembangan ekowisata di Kabupaten Siak 2.Kendala dalam pengembangan ekowisata di Kecamatan Mempura Kabupaten Siak.Hasil penelitian dijelaskan bahwa Pengembangan kawasan ekowisata di Kecamatan Mempura masih terbilang belum Maksimal dikarenakan masih banyak kendala yang dihadapi oleh pemerintah daerah Mempura.

Kata Kunci: Kebijakan, Pengembangan, Ekowisata.

\section{PENDAHULUAN}

Kebijakan publik merupakan rangkaian pilihan-pilihan yang saling berhubungan yang dibuat oleh lembaga atau pejabat pemerintah pada bidang-bidang yang menyangkut tugas pemerintahan, yang salah satunya adalah kepariwisataan.Penyelenggaraan usaha kepariwisataan merupakan salah satu potensi untuk di kembangkan di daerah. Di samping dapat meningkatkan pendapatan masyarakat tempatan,juga dapat meningkatkan Pendapatan Asli Daerah. Oleh karena itu kepariwisataan perlu dilakukan pembinaan,pengawasan,dan pengendalian oleh pemerintah daerah,sehingga mampu memberikan manfaat dengan tetap memberikan nilai nilai sosial budaya dan agama.

Salah satu sasaran untuk meningkatkan sektor non migas adalah dengan meningkatkan kontribusi pariwisata dalam perolehan devisa sehingga sektor pariwisata diharapkan mampu menjadi salah satu penghasil terbesar PAD kabupaten Siak. Berdasarkan hal tersebut, maka kebijakan pembangunan 
kepariwisataan diarahkan untuk meningkatkan efektifitas pemasaran pariwisata melalui kegiatan promosi dan pengembangan produk-produk wisata serta meningkatkan sinergi dalam jasa pelayanan pariwisata.Salah satu bentuk kegiatan pariwisata yang berwawasan lingkungan dengan mengutamakan aspek konservasi alam,aspek pemberdayaan sosial budaya,aspek ekonomi masyarakat lokal serta aspek pembelajaran dan pendidikan. Disebut dengan ekowisata (Ekotourism.)

Ekowisata dimulai ketika dirasakan adanya dampak negatif pada kegiatan pariwisata konvensional. Dampak negatif ini bukan hanya dikemukakan dan di buktikan oleh para ahli lingkungan tetapi juga para budayawan,tokoh masyarakat dan pelaku bisnis pariwisata itu sendiri.Salah satu destinasi pariwisata di Riau adalah Kabupaten Siak yang belum lama diresmikan sebagai Kota Pusaka. Visi Kabupaten Siak yaitu "Terwujudnya Kabupaten Siak Yang Maju Dan Sejahtera Dalam Lingkungan Masyarakat Yang Agamis Dan Berbudaya Melayu Serta Menjadikan Kabupaten Siak Sebagai Tujuan Pariwisata Di Sumatera".Secara geografis Kabupaten Siak memiliki posisi strategis berada pada kawaasan pesisir pantai yang berhampiran dengan sejumlah negara tetangga dan masuk kedalam daerah segitiga pertumbuhan (growth triagel) Indonesia- Malaysia- Singapura.

Kabupaten Siak,tepatnya Kecamatan Mempura merupakan awal dari pemerintahan Kerajaan Siak pada masa Sultan Abdul Jalil Rahmat Syah (Raja Kecik). Kemudian dengan bergantinya Kepemimpinan pada masa Sultan Assyaidis Syarif Ali Abdul Jalil Syaifuddin (1784-1810M) beliau memindahkan Pusat Pemeritahan dari Mempura Ke Siak Kota.Pada Tahun 2005 kelurahanMempura berubah menjadi Kecamatan Mempura.Kecamatan Mempura memiliki berbagai macam potensi pariwisata yang dapat dikembangkan untuk meningkatkan kesejahteraan masyarakat, untuk itulah alasan penelitian ini berada di Kelurahan sei mempura. Yang nantinya akan di kembangkan menjadi daerah Ekowisata. Perkembangan suatu daerah, khususnya di Mempura akan meningkatkan daya tarik wisatawan lokal maupun manca negara yang nantinya akan berpotensi sebagai Sumber Penerimaan Pendapatan Asli Daerah dari sektor pariwisata. Selain itu juga dapat meningkatkan daya saing dan perkembangan masyarakat setempat.Beberapa potensi obyek wisata dan daya tarik wisata dimiliki pemerintah Mempura adalah sebagai berikut :

1. Potensi ekologi(alam)

Menjadikan sebagian kawasan Mempura sebagai kawasan konservasi (hutan dan DAS) yang nantinya dapat menjadi laboratorium alam yang berpotensi sebagai objek wisata alam yang bernilai pendidikan.

2. Potensi Sosial Budaya

Keberadaan kesenian dan budaya tradisional lokal yang merupakan warisan masyarakat melayu masa lalu sangat potensial untuk dijadikan daya tarik kunjungan wisata bagi pemerhati budaya dan sebagai hiburan yang menarik bagi masyarakat umum. Pengembangan dengan melakukan pembinaan dan penyelenggaraan pertunjukan secara berkala.

3. Potensi sejarah

Kebesaran Kerajaan Siak di masa lalu menjadikan peninggalan sejarah yang dimilki kawasan Mempura sangat potensial untuk mendatangkan kunjungan wisatawan. Pengembangan dilakukan dengan pemugaran ,rekonstruksi bangunan yang sudah rusak atau bahkan duplikasi bagi bangunan banguan yang telah punah. Hal ini untuk membangkitkan kembali suasana lingkungan seperti halnya suasana dimasa lalu. Destinasi sejarah budaya yang bisa dinikmati wisatawan di Kecamatan Mempura meliputi: Tangsi Belanda, Makam Sultan Buang Asmara, Rumah dan Kantor Kotler, Rumah Datuk Pesisir, Makam Kubah, Kantor Wedana di Benteng Hilir.

4. Potensi Pertanian dan perkebunan.

Kondisi tanah yang subur dalam sebagian kawasan serta adanya potensi perkebuana buah lokal (durian, manggis dan duku ) yang berumur puluhan tahun menjadi sangat potensial untuk dijadikan daya tarik wisata kawasan. Bentuk pengembangan selain melakukan pelestarian terhadap kebun kebun tua ini juga dengan melakukan penanaman tanaman baru untuk menggantikan tanaman yang mulai mati termakan 
usia. Selain itu ketersediaan ruang-lahan yang luas dan kurang menghasilkan pada halaman masyarakat dapat dimanfaatkan dengan menanam berbagai jenis tanaman sayur dan buah dengan harapan dapat memberikan nilai tambah pada lahan dan dapat pula menjadi tambahan daya tarik wisata dalam kawasan.

Dari potensi yang dimiliki Kecamatan Mempura dapat menjadikan terwujudnya kawasan Ekowisata sehingga di butuhkan pengembangan dalam pelestarian alam yang dimiliki agar dapat dimanfaatkan dan mampu menambah PAD Mempura sesuai dengan kebijakan yang terkait dengan pengembangan Daerah Ekowisata seperti yang tertuang dalam Peraturan Menteri Dalam Negeri Nomor 33 tahun 2009 tentang pedoman pengembangan Ekowisata Daerah,dimana kegiatan ekowisata memanfaatkan potensi wisata yang ada seperti potensi keindahan alam, potensi sosial budaya masyarakat keunggulan sejarah dan potensi di bidang pertanian dan perkebunan. Berdasarkan uraian tersebut diatas peneliti tertarik untuk melakukan penelitian dengan judul "Pengembangan Kawasan Ekowisata mempura Kabupaten Siak".

Berdasarkan latar belakang penelitian diatas,maka rumusan masalah yang akan diteliti oleh penulis adalah:Bagaimana Pengembangan Kawasan Ekowisata dan Kendala didalam Pengembangan Kawasan Ekowisata Mempura Kabupaten Siak.Pariwisata merupakan segala sesuatu yang berhubungan dengan wisata terutama pengusahaan objek dan daya tarik wisata serta usaha yang terkait dengan bidang tersebut. Pariwisata atau tourism adalah fenomena yang meliputi perpindahan ke dan tempat tujuan di luar tempat tempat tinggal sehari-hari (Anwar, 2012: 14) .

Menurut Theobald (2013: 17) pariwisata adalah sejumlah gejala dan hubungan yang timbul, mulai dari interaksi antara wisatawan di satu pihak, perusahaan-perusahaan yang memberikan pelayanan kepada wisatawan dan pemerintah serta masyarakat yang bertindak sebagai tuan rumah dalam prosesmenarik dan melayani wisatawan dimaksud. Sementara itu kepariwisataan merupakan keseluruhan kegiatan pemerintah, dunia usaha, dan masyarakat yang ditujukan untuk menata kebutuhan perjalanan dan persinggahan (Jannieson et. al., 2013: 2). Kepariwasataan ini melibatkan pergerakan barang, jasa dan orang-orang di seluruh dunia, oleh karenanya menjadi yang paling terlihat di dalam pengungkapan globalisasi (Reisinger, 2013: 8).

Ecotourism yang dalam bahasa Indonesia diterjemahkan menjadi "ekowisata", juga "eko pariwisata", "wisata ekologi", "pariwisata ekologi", menurut Hector Ceballos-Lascurian, ekowisata terdiri dari berwisata, mengunjungi kawasan alamiah yang relatif tidak terganggu, dengan niat betul-betul obyektif untuk melihat, mempelajari, mengagumi keindahan alam, flora, fauna, termasuk aspek-aspek budaya baik di masa lampau maupun masa sekarang yang mungkin terdapat di kawasan tersebut.

Ekowisata juga berarti melibatkan masyarakat setempat dalamproses dan mereka dapat memperoleh keuntungan sosial ekonomi dariproses tersebut. Proses ini juga meliputi petunjuk-petunjuk ketat yangdiletakkan oleh berbagai pejabat penguasa sehingga fluktuasi wisatawanyang tiba sekurangkurangnya membawa pengaruh negatif palingminimal terhadap lingkungan kawasan tersebut (Nyoman S. Pendit, 2010: 170).

Damardjati dalam istilah-istilah dunia pariwisata menyebutkan bahwa Ekowisata merupakan usaha dan kegiatan kepariwisataan dengan penyelenggaraan perjalanan ke daerah-daerah lingkungan alam, disertai kesadaran penuh tentang adanya tanggung jawab yang tinggi terhadap pelestarian lingkungan alam dan peningkatan kesejahteraan penduduk setempat. Saleh (2000) menyatakan bahwa untuk mengusahakan ekowisata di suatu tempat, yang perlu dikenali adalah keadaan alam (keindahan dan daya tarik) yang spesifik atau unik dari objek wisata yang bersangkutan, prasarana yang tersedia (lancar/tidak lancar, nyaman/tidak nyaman, sudah lengkap, masih harus diadakan, atau dilengkapkan), tersedianya sumberdaya manusia (yang terlatih maupun yang dapat dilatih), tingkat pendidikan dan budaya masyarakatnya.

Istilah ekowisata tergolong masih baru di Indonesia. Awalnya terjemahan langsung dari Ecotourism masih belum baku. Ada yang menterjemahkannya dengan wisata lingkungan, wisata ekologis, dan ekowisata. Dirjen pariwisata menggunakan istilah ekowisata dengan makna ecotourism. 
Sementara itu, pengertian ekowisata menurut kantor Menteri Negara Lingkungan Hidup adalah "wisata alam bentuk perjalanan ke tempat-tempat di alam terbuka yang relative belum terjamah atau tercemar dengan tujuan khusus mempelajari, mengagumi dan menikmati pemandangan dengan tumbuh-tumbuhan dan satwa liarnya (termasuk potensi kawasan berupa ekosistem, keadaan iklim, fenomena alam, kekhasan jenis tumbuhan dan satwa liar), juga semua manifestasi kebudayaan yang ada trmasuk tatanan lingkungan social budaya, baik dari masa lampau maupun masa kini di tempat-tempat tersebut dengan tujuan untuk melestarikan lingkungan dan meningkatkan kesejahteraan masyarakat setempat". Pengertian tersebut menunjukkan bahwa ekowisata berakar pada kegiatan wisata alam, di daerah-daerah yang masih alami atau dilindungi yang didasarkan pada funsi ekologis, linkungan sebagai komponen penting dalam hubungan saling terkait dengan aspek ekonomi dan social dalam menunjang kelangsungan wisata tersebut (Kurniawan dan Burhanuddin, 2004).

Kegiatan ekowisata antara lain bertujuan untuk mengembangkan kegiatan ekonomi yang ramah lingkungan, sehingga kelestarian ekosistem dapat terjaga. Sebelum mengembangkan ekowisata, harus ada persyaratan ekologis, kelayakan sosialekonomi, dan sarana prasarana suatu kawasan wisata yang harus dipenuhi, agar dapat menjadi objek ekowisata yang menarik, memberikan keuntungan bagi masyarakat lokal dan juga dapat memuaskan para pengunjung (Tuwo, 2011).

\section{METODE}

Penelitian ini dilakukan di lokasi Ekowisata Kecamatan Mempura Kabupaten Siak. Tujuan dilakukan penelitian ini yaitu untuk melihat pengembangan kawasan ekowisata Mempura Kabupaten Siak dan mengetahui faktor hambatan dalam pelaksanaan kebijakan pengembangan kawasan ekowisata Mempura Kabupaten Siak.Peneliti menggunakan beberapa teknik pengumpulan data, yakni: Observasi, wawancara mendalam (indepth interview) dan dokumentasi. Pada penelitian ini informan yang kami wawancarai adalah orang-orang yang terlibat dalam penelitian yang akan memberikan informasi atau jawaban mengenai apa yang menjadi objek penelitian, yakni: Kepala Dinas Pariwisata,Camat Kecamatan Mempura,Kades-Kades yang Ada di Kecamatan Mempura dan Masyarakat.

Anlisis data dalam penelitian ini menggunakan metode kualitatif melalui interpretasi etik dan emik. Dalam penelitian kualitatif informasi etik merupakan pandangan dari peneliti berdasarkan pada teori dan konsep yang ada, dan informasi emik merupakan pandangan dari informan. Data yang diperoleh di lapangan merupakan data emik yang akan mendukung data etik yang bersumber dari teori yang dimiliki oleh peneliti sebelum turun ke lapangan (Moleong, 2016:51).

\section{HASIL DAN PEMBAHASAN}

1) Pengembangan daerah kawasan ekowisata di Kecamatan Mempura Kabupaten Siak.

Untuk menganalisis tentang masalah penelitian ini, yakni pengembangan kawasan ekowisata yang ada diKecamatan Mempura Kabupaten siak, ditinjau dari beberapa indikator berdasarkan teori pengembangan kawasan ekowisata menurut tuwo (2011), mengembangkan ekowisata, harus ada persyaratan ekologis, kelayakan sosial ekonomi, dan sarana prasarana yang harus dipenuhi. Keseluruhan indikator penelitian tersebut didapatkan jawabannya berdasarkan wawancara bebas terpimpin secara mendalam dengan responden, sehingga didapati apakah indikator yang telah ditetapkan tersebut dapat direalisasikan dengan efektif dan efesien. Berikut akan dipaparkan hasil penelitian yang didapat dari hasil wawancara bebas terpimpin dengan responden yang telah ditetapkan dan analisis yang dilakukan peneliti 
dari responden yang diambil sesuai kebutuhan penelitian sebagaimana yang telah ditetapkan dalam penelitian ini.

\section{Ekologis}

Secara ekologis Kecamatan Mempura memiliki ekowisata yang menarik untuk dikembangkan. Dilihat dari alam yang sangat kayaakan hutan dan kebununtuk dikembangkan, seperti:

a. Daerah Aliran Sungai (DAS)

Kecamatan Mempura secara Geografis merupakan daerah Lembah atau Daerah dikelilingin oleh Aliran Sungai siak. Dapat diketahui dari 8 (delapan) Kelurahan 4 Kelurahan merupakan daerah aliran Sungai, yaitu Desa Kampung Tengah, Sungai Mempura, Desa Merempan Hilir dan Desa Teluk Merempan. Sepanjang daerah aliran sungai Siak berpotensi untuk dapat dikembangkan menjadi daerah wisata dengan dibangunnya Turab-turab.Di kampung Teluk merempan Daerah Aliran Sungai sangat dimanfaatkan masyarakat untuk mencari ikan yang menjadi salah satu sumber pendapatan masyarakat. Berdasarkan hasil wawancara dengan beberapa narasumber sebagai berikut :

"Dulu sungai siak selain sebagai salah satu alternativlewatnya kapal-kapal juga menjadi salah satu wadah mata pencarian masyarakat, banyak masyarakat yang tinggal di daerah aliran sungai menjadi nelayan, kalau sekarang masih ada juga nelayan namun sudah berkurang karena sudah banyak masyarakat berkebun dan sebagainya ". ( OK. Mohd.Rendra DP selaku camat Mempura). "Sungai ini berpotensi menjadi wisata seperti yang di sampaikan tadi kita merencanakan wisata air seperti kapalkapal yang membawa pengunjung untuk melihat kota siak dari sungai. Ini sudah kita bicarakan sama dinas pariwisata." ( Drs. Syaifullah, MM selaku Sekcam Mempura).

"bagi kami sungai ini sangat membantu juga kalau dulu sebelum ada jembatan banyak masyarakat yang mau nyeberang pakai kapal, kalau sekarang udah ada jembatan jadi sebagai mata pencarianlah buat orang-orang tua kami yang menjadi nelayan" ( salah seorang masyarakat kampung Benteng Hilir)

Dari hasil wawancara diatas dapat disimpulkan bahwa daerah aliran sungai di kecamatan Mempura berpotensi dijadikan sebagai objek wisata sesuai dengan pernyataan bapak sekcam mempura yang telah merencanakan wisata air yaitu kapal yang dapat membawa pengunjung untuk melihat kota Siak dari sungai.

b. Hutan

Kecamatan Mempura memiliki Hutan yang cukup luas.Namun hutan yang ada di Kecamatan Mempura tidak dimanfaatkan sebagai penghasil kayu tetapi hutan Mempura memiliki nilai Produk Buah yang memberikan Kontribusi terbesar terhadap pendapatan masyarakat Kecamatan Mempura.Adapun hasil hutan bukan kayu berupa: Buah Durian; menghasilkan sekitar 257.250 Juta/Tahun (90,15\%). Manggis menghasilkan 13.5 juta/ tahun (4, 73\%), dan rambutan menghasilkan 14,6 juta/ Tahun (5,12\%). Selain itu di Kampung Merempan Hilir Kecamatan Mempura Hutan Akan dijadikan daerah wisata berupa Sekolah Alam yang masih dalam proses. Berdasarkan hasil wawancara dengan beberapa narasumber :

"Hutankita ni cukup luas sebenarnya, dikampung Merempan Hilir ini kami sudah mulai membuka lahan untuk dijadikan sekolah alam yang nantinya jadi objek wisata dikampung kita ini." ( Tengku Mukhlis selaku Kades kampung Merempan Hilir).

“ Besok dikampung kita ada tempat baru, sekarang kami sedang buka lahan untuk sekolah alam.” (Bapak Fauzan Azima selaku Ketua Karang Taruna Kampung Merempan Hilir).

Dari hasil wawancara diatas dapat disimpulkan bahwa hutan di Kecamatan Mempura cukup luas dan memiliki potensi dijadikan kawasan ekowisata yang memberikan kontribusi kepada masyarakat.

Selain Daerah Aliran Sungai dan hutan Kecamatan Mempura juga memiliki daerah bersejarah, dilihat dari beberapa ekowisata yang ada di Menpura seperti:

1. Tangsi Belanda

2. Makam Sultan Buang Asmara

3. Rumah dan Kantor Kotler 
4. Rumah Datuk Pesisir

5. Kantor Wedana di Benteng Hiril

6. Makam Kubah

Dari berbagai potensi ekowisata diatas terlihat banyak objek wisata di Kecamatan Mempura Kabupaten Siak sangat bernilai sejarah pada masa zaman kerajaan hingga saat ini.Namun objek wisata yang ada di Kecamatan Mempura tidak terekspos oleh masyarakat luar. Objek wisata dikecamatan mempura masih belum dilestarikan,dibuktikan dari hasil wawancara dengan salah satu narasumber :

"Banyak wisata yang ada di sini sebenarnya,namun masih semak dan belum digarap, karena pengembangan wisata di Siak masih terfokus di Kecamatan Siak Kota" ( Drs. Syaifullah, MM selaku Sekcam Mempura, 3 Januari 2018).

" kalau wisata di Kec. Mempura ini ya banyak tapi pengunjung sedikit, orang lebih banyak ke kota Siaknya, karena objek wisata yang ada disini tak terurus" ( salah seorang masyarakat, 3 Januari 2018).

Dari hasil wawancara diatas dapat disimpulkan bahwa secara ekologis Kecamatan mempura memiliki kawasan ekowisata yang sangat banyak dilihat dari segi alam dan sejarahnya, namun dari berbagai objek wisata tersebut masih belum berkembang, dikarenakan pengembangan wisata masih terfokus di Kecamatan Siak Kota serta banyak tempat wisata yang ada tidak terawat sebagaimana mestinya.Seperti salah satu objek wisata yang berada di kampung Benteng Hulu yaitu Tangsi Belanda yang saat ini sudah terlihat usang bagai bangunan tua.

\section{Sosial Ekonomi}

Adalah segala sesuatu yang berkaitan dengan pemenuhan kebutuhan masyarakat, antara lain sandang, pangan, perumahan, endidikan, kesehatan dan lain-lain.Pemenuhan kebutuhan tersebut berkaitan dengan penghasilan.

Dari segi sosial ekonomi Kecamatan Mempura dapat di tinjau dari beberapa indikator :

a. Penduduk

b. Pendidikan

c. Mata pencarian

d. Kesehatan

Dilihat dari sudut pandang sosial ekonomi secara kesuluruhan masyarakat Kecamatan Mempura memiliki nilai sosial ekonomi yang cukup rendah dikarenakan masyarakat di Kecamatan Mempura belum mampu memanfaatkan ekowisata sebagai salah satu sumber perekonomian masyarakat secara terus menerus tapi hanya pada saat adanya kegiatan/ acara-acara serta musim buah.Ini didukung dengan pernyataan yang disampaikan oleh narasumber sebagai berikut :

"Seharusnya, kawasan ekowisata dapat membantu meningkatkan ekonomi rumah tangga didaerah lokal, namun seiring dengan menurunya animo masyarakat atau kunjungan wisatawan yang berkurang menyebabkan berkurangnya penghasilan ataupun pendapatan ekonomi masyarakat local".(O.K. Mohd Rendra DP, SSTP selaku Camat Mempura).

Dari data dan hasil wawancara di atas dapat disimpulkan bahwa secara sosial penduduk kecamatan Mempura masih mampu melestarikan budaya lokal. Sedangkan secara ekonomi dikecamatan Mempura masih tergolong rendah, banyak ekonomi rumah tangga yang belum memadai seperti minimnya ibu-ibu rumah tangga yang berperan dalam membantu ekonomi keluarga.

3. Sarana prasarana

Prasarana adalah segala sesuatu yang merupakan penunjang utama terselenggaranya suatu proses. Adapun proses tersebut dapat berupa suatu usaha, pembangunan, atau proyek. Prasarana ekowisata yang ada di Kecamatan Mempura yaitu adanya akses jalan dan jembatan yang sudah bagus. Diantaranya ada jembatan Siak (Jembatan Tengku Agung Sultanah Latifah) sebagai penghubung Kecamatan Mempura dengan Kecamatan Siak Kota, Jembatan Kupu-Kupu yang berada di Kecamatan Mempura tepatnya dikampung tengah sebagai akses jalan masuk kepemukiman masyarakat, tempat menuju makam-makam 
dan Rumah Datuk Pesisir.Dan Jembatan-jembatan penghubung antar kampung. Diperkuat dengan hasil wawancara dari beberapa narasumber :

“ Untuk menuju tempat wisata saya rasa sudah bagus, jalan-jalan juga sudah sangat mendukung, jembatan juga bagus dan kokoh. Kalau pakai mobil sudah bisa sampai ketempat wisatanya langsung, kalau akses jalan ya sudah baiklah". (Drs. Syaifullah, MM selaku Sekcam Mempura, 3 Januari 2018).

" Jalan disini sudah aspal dan elok kalau dulu jalan kita masih jelek dan berlobang- lobang sekarang sudah alhamdulillah bisa langsung sampai ke tempat wisatanya". ( Mariam sekalu masyarakat kampung Benteng Hilir).

Sedangkan sarana adalah segala sesuatu yang dapat dipakai sebagai alat dalam mencapai maksud dan tujuan. Dengan kata lain sarana lebih ditujukan untuk benda atau peralatan yang bergerak.Di Kecamatan mempura belum ada terlihat sarana yang mendukung objek wisata yang ada, seperti tidak adanya toilet di setiap objek wisata, tidak adanya transportasi wisata seperti sampan dan kereta wisata.Dari hasil wawancara diatas dapat di simpulkan bahwa di Kecamatan Mempura Prasarana sudah bagus dilihat dengan akses jalan yang sudah baik menuju tempat wisata, namun sarana dikecamatan Mempura belum bisa dikatakan bagus dikarenakan belum adanya transportasi pendukung untuk mempermudah pengunjung menuju tempat wisata.

2) Kendala dalam Pengembangan Kawasan Ekowisata di Kecamatan Mempura Kabupaten Siak.

Kendala yang peneulis temui dalam pengembangan Kawasan ekowisata Kecamatan mempura diantaranya yaitu:Support Pemerintah yang Minim, Tidak Adanya Support Masyarakat, Terbatasnya Anggaran, Kurangnya Sosialisasi dan Sarana Prasarana yang minim di Pemerintahan Kecamatan Mempura Kabupaten Siak.

\section{KESIMPULAN}

Berdasarkan hasil penelitian pengembangan ekowisata di kecamatan Mempura Kabupaten Siak masih belum berjalan dengan baik dan belum maksimal dalam pengembangan objek wissata. Ada 8 objek wisata yang ada di Kecamatan Mempura yaitu Tangsi Belanda, Rumah Datuk Pesisir, makam kubah, makam Sultan Tengku Buang Asmara, Jembatan Kupu-Kupu, Rumah dan Kantor Kotler, Kantor Wedana, dan jembatan penghubung antar kampung. Dari wisata-wisata yang diatas banyak yang masih belum terawat dengan baik, selain itu lahan objek wisata bukanlah milik pemerintah daerah melainkan milik masyarakat kecamatan Mempura. Adapaun kendala dalam pengembangan ekowisata di Kecamatan Mempura Kabupaten Siak yaitu pemerintah, Masyarakat, anggaran, sosialisasi dan sarana.

\section{DAFTAR PUSTAKA}

[1]. Attar, Muhammad, Hakim, Luchman, dan Yanuwiadi, Bagyo. 2013. "Analisis Potensi Dan Arahan Strategi Kebijakan Pengembangan Desa Ekowisata Di Kecamatan Bumiaji-Kota Batu". Journal of Indonesian Tourism and Development Studies, Vol.1, No.2, hlm. 68-78

[2]. Bougdan. R dan SK. Biklen. 2012. Qualitative research for Education An Introduction to the Theory and Methods. Boston: Allyn and Bacon.

[3]. Dunn, William N. 1981. Pengantar Analisis Kebijakan Publik, Penyunting Muhadjir Darwin. Edisi Kedua. Cetakan Pertama. Yogyakarta: Gadjah Mada University Press. 
[4]. Dye, Thomas R. 1987.Understanding Public Polic.Engelewood Chief, New Jersey: Prentince-Hall Inc.

[5]. Fandeli, Chafid dan Mukhson. 2000. Pengusahaan Pariwisata. Yogyakarta: Pustaka Pelajar Offset.

[6]. Fandeli.C, 2001.Dasar-Dasar Manajemen Kepariwisataan Alam. Yogyakarta: Liberty.

[7]. Grindle, Merilee S. 1980. Politics and Policy Implementation in The Third World. New Jersey: Princnton University Press.

[8]. Hadi, S. P. 2007. "Pariwisata Berkelanjutan (Sustainable Tourism)".Makalah Seminar Sosialisasi Sadar Wisata, Edukasi Sadar Wisata bagi Masyarakat di Semarang.

[9]. Henry, Nicholas. 2008. Public Administration and Public Affairs, New York: Prentice Hall.

[10]. Hogwood, Brian W., and Lewis A.Gunn. 1978. Policy analysis for the real world. Oxford Univeristy Press.

[11]. Jannieson, Walter, Harold Goodwin and Christopher Edmunds. 2013. "Contribution Of Tourism To Poverty Alleviation", Transport Policy and Tourism Section Transport and Tourism Division, pp. 138.

[12]. Nasir, Yendri. 2015. Kebijakan pengembangan kawasan ekowisata mempura siak,

[13]. Karsudi, Soekmadi, Rinekso, dan Kartodihardjo, Hariadi. 2010. "Strategi Pengembangan Ekowisata di Kabupaten Kepulauan Yapen Provinsi Papua". JMHT, Vol. XVI, No. 3, hlm. 148-154.

[14]. Kurniawan. J., dan Burhanuddin, 2004. Pengembangan Ekowisata di Kawasan Ekosistem Leuser. Medan: Program Pengembangan Leuser.

[15]. Marpaung. H. 2002. Pengantar Kepariwisataan. Bandung: Alfabeta.

[16]. Mazmanian, Daniel H. dan Paul A. Sabatier. 1983. Implementation and Public Policy, New York: HarperCollins.

[17]. Moleong, Lexy. 2011. Metode Penelitian Kualitatif. Bandung: PT. Remaja Rosdakarya.

[18]. Nugroho, Riant, D. 2004. Kebijakan Publik : Formulasi, Implementasi, dan Evaluasi. Jakarta: Elex Media Komputindo.

[19]. Nugroho, 2011. Ekowisata dan Pembangunan Berkelanjutan, Yogyakarta: Pustaka Pelajar.

[20]. Pendit, Nyoman S. 2010. Ilmu Pariwisata Pengantar Perdana. Jakarta : Pradnya Paramita.

[21]. Saleh, W., 2000.Pengelolaan Perusahaan Bidang Ekowisata. Yogyakarta: Fakultas Kehutanan. Universitas Gadjah Mada. 
[22]. Simanjuntak, YMN. 2009. “Analisis Nilai Ekonomi dan Sosial Ekowisata Tangkahan (Studi Kasus di Desa Namo Sialang dan Desa Sei Serdang Kecamatan Batang Serangan Kabupaten Langkat Sumatera Utara), Jurnal Pariwisata Indonesia, Vol. 9, No. 12.

[23]. Sukmana, Oman. 2009. "Model Pengembangan Lingkungan Kota Ekowisata (Studi Di Wilayah Kota Batu)". HUMANITY, Vol. V, No. 1, hlm. 42-47.

[24]. Theobald William F. 2013. Global Tourism. New York: Elsevier Inc.

United Nations, 2012, "Poverty Alleviation Through Sustainable Tourism Development", Economic And Social Commission For 